\title{
Effect of salinity and drought on the survival of Biomphalaria arabica, the intermediate host of Schistosoma mansoni in Saudi Arabia
}

\author{
Osama M. S. Mostafa \\ Zoology Department, Faculty of Science, Ain Shams Univ., Abbassia 11566, Cairo, Egypt. \\ e-mail: osamamostafa@hotmail.com
}

\section{ABSTRACT}

The effect of salinity and drought as two important abiotic factors on the survival of Biomphalaria arabica, the intermediate host of Schistosoma mansoni in Saudi Arabia was studied in the laboratory. Saudi B. arabica snails were collected from freshwater bodies in Abha, Asser district, Saudi Arabia. Snails were exposed to ten concentrations of Sodium Chloride as follow: 1, 2, 3, 4, 5, 6, 7, 8, 9, 10\%o. In addition, snails were exposed to a series of Sodium Chloride concentrations lie between the concentration that produced $100 \%$ mortality and the concentration lies previous to it. In drought experiments, the snails were exposed to complete dryness for 12, 24, 36 and 48 hours and the snails in moist soil were examined daily for fifteen days. The results revealed that B. arabica snails remain alive to $5 \% \mathrm{NaCl}$ concentration and $100 \%$ mortality occurred at $7.2 \%$ of $\mathrm{NaCl}$ concentration. On the other hand, the ability of the snails to resist the complete dryness appeared to be limited, since $100 \%$ mortality was achieved after 36 hours in absence of lettuce leaves and after 48 hours in the presence of lettuce leaves. The snails in moist soil provided with fresh lettuce leaves remain survive to 15 days without any death. In the case of snails in the moist soil without fresh lettuce leaves, the survival was unaffected until $10^{\text {th }}$ day post-exposure, while further increases in exposure period resulted in reductions in survival up to $50 \%$ for snails exposed for 15 days. The present investigation declared that $B$. arabica has a great resistance to salinity increase and this may be explain why B. arabica has a great abundance in KSA. However, the ability of $B$. arabica snail to resist the dryness appeared to be limited.

Key words: salinity, drought, survival, Biomphalaria arabica, Schistosoma mansoni, Saudi Arabia.

\section{INTRODUCTION}

Approximately 200 million people in 74 countries are infected with schistosomes; 120 million are symptomatic, and 20 million suffer severe illness (Chitsulo et al., 2000\& Ross et al., 2002). Schistosomiasis is the most important human helminth infection in terms of morbidity and mortality; a recent meta-analysis assigned 2 to $15 \%$ disability weight to the disease (King et al., 2005). The prevalence rate of schistosomiasis in Kingdom of Saudi Arabia (KSA) was 2.2/ 100,000; the percentage of urinary schistosomiasis caused by Schistosoma haematobium was $33.4 \%$ while that of the intestinal schistosomiasis caused by $S$. mansoni was $66.6 \%$ (Health Statistical Year Book of the Ministry of Health in KSA, 2006). In KSA, it has been found that snail of species Biomphalaria arabica acts as the intermediate host for S. mansoni (Arfaa, 1976).

Abiotic components are non-living chemical and physical factors in the environment, some authors studied the effects of these factors on the biology of 
medically important snails. Yasuraoka (1961) reported on the effect of hydrogen ion concentration and salinity of water on extruding response and survival of Oncomelania nosophora the vector snail of S. japonicum in Japan. Gretillat and Gaston (1975) studied the effect of salinity on some aquatic vector snails in the Dallols' region, Niger, Africa. Leveque et al. (1978) tested the effects of some medium factors on the fecundity of Biomphalaria glabrata under laboratory conditions. Donnelly et al. (1983) evaluated the influence of salinity on certain biological aspects of the of Bulinus (Physopsis) africanus. Diaw et al. (1988\& 1989) studied the resistance of $B$. umbilicatus and B. senegalensis, vectors of human and animal trematode infections in Senegal, to drought under laboratory and natural conditions. Kefford and Nugegoda (2005) measured the growth and reproduction of the freshwater snail Physa acuta at various salinity levels.

Sometimes the resistance of the snail to abiotic factors is affected by parasitism, Badie and Rondelaud (1982) studied the effect parasitism on the resistance of Cionella lubrica the intermediate host of Dicrocoelium lanceolatum to temperature and desiccation. Moreover, Lwambo et al. (1987) found that the infectivity of miracidia of $S$. mansoni in B. arabica was influenced by some factors such as water temperature and salinity.

In addition, the variations in abiotic factors have a strong influence on the distribution and the density of the snails and as a result on the prevalence and distribution of helminth parasites. Rogowski and Stockwell (2006) explained the relationship between salinity, snails, parasites and White Sands pupfish (Cyprinodon tularosa) in New Mexico State. Ibrahim (2007) determined the infection prevalence and intensity of Angiostrongylus cantonensis in freshwater snails in relation to some ecological and biological factors at Al-Salam irrigation Canal and Al-Abtal village, North Sinai, Egypt. The influence of climatic conditions on the prevalence and transmission of helminth parasites in a terrestrial molluscan population was studied in a grassland site in southern England by Morley and Lewis (2008).

The present article was aimed to study the effect of two important abiotic factors: salinity and drought on the survival of Biomphalaria arabica, the intermediate host of Schistosoma mansoni in Saudi Arabia.

\section{MATERIAL AND METHODS}

Snails: Saudi B. arabica snails with diameter ranged from 5 to $8 \mathrm{~mm}$ (mean $6.9 \mathrm{~mm}$ ) were collected from freshwater bodies in Abha, Asser district, Saudi Arabia. The first generation of $B$. arabica snails was used in the present investigation to be sure that the snails were clean and free from any pathogens.

Salinity experiment: ten concentrations of Sodium Chloride $(\mathrm{Na} \mathrm{Cl})$ were prepared in deionized distilled water as follow: 1, 2, 3, 4, 5, 6, 7, 8, 9, 10\%. Control experiments were performed with deionized water alone. Tests were performed in 24well plates; snails were placed individually in the wells with about two $\mathrm{ml}$ of tested saline concentration. To prevent the snails from crawling out of the wells, the wells were covered and the space between the solution and the cover didn't allow the snails to leave the solution. Groups of ten snails were exposed to each of saline concentration for 24 hours, and then the snails were transferred to dechlorinated water for another 24 hours for recovery. After this period, the snails were examined with the help of stereoscopic microscope to count the dead and living snails to calculate the mortality percentage. The death of the snails was confirmed by contraction of the soft parts within the shell, absence of muscle contractions in response to needle probe and 
change in the shell color. In addition, snails were exposed to a series of $\mathrm{NaCl}$ concentrations lie between the concentration that produced $100 \%$ mortality and its previous concentration. All experiments were independently repeated three times.

Drought and starvation experiment: 38 Petri dishes of $9 \mathrm{~cm}$ diameter were supplied with sterilized soil, the dishes were divided into two groups: the first one consists of 8 dishes contain completely dry soil; ten snails were placed in each dish; four dishes of them were supplied with small pieces of fresh lettuce leaves and the other dishes were not supplied. The snails were exposed for 12, 24, 36 and 48 hours. The second group consists of 30 dishes contain moist soil; ten snails were placed in each dish; fifteen dishes of them were supplied with small pieces of fresh lettuce leaves and the other fifteen dishes were not supplied. The snails were examined daily for fifteen days. Control experiments were performed with dechlorinated water. After the exposure period, the snails were transferred to dechlorinated water for 24 hours for recovery, and then examined with the help of stereoscopic microscope to count the dead and living snails to calculate the mortality percentage. All experiments were independently repeated three times.

\section{RESULTS AND DISCUSSION}

Increasing of salinity in rivers and wetlands is a serious environmental problem on all inhabited continents (Williams, 1987), and is likely to affect aquatic organisms (Hart et al., 1990, 1991). Recently, there has been interest in the lethal effects of high salinity on fresh water macroinvertebrates (Kefford and Nugegoda 2005). The present results (Tables $1 \& 2$ ) declared that $B$. arabica has a great resistance to salinity increase, since they remain alive to $5 \%$ NaCl concentration and $100 \%$ mortality occurred at $7.2 \%$ of $\mathrm{NaCl}$ concentration. This result was correlated with that of Donnelly et al. (1983) who reported that the survival of adult $B$. africanus was unaffected in salinities $<3.5 \%$ while further increases in salinity resulted in significant reductions in survival up to a lethal salinity of $8.7 \%$, which caused 100\% mortality within 24 hours. In addition, Leveque et al. (1978) reported that B. glabrata snail is not affected by very high rates of concentrations of $\mathrm{Na}, \mathrm{Ca}$, $\mathrm{Mg}$, and K-salts but eggs' laying is getting down when the amount of $\mathrm{NaCl}$ is between 2000 and $4000 \mathrm{mg} / 1$. The high resistance of $B$. arabica to salinity may be explain their great abundance in KSA (Browen and Wright, 1980). Moreover, the great tolerances of this snail to high salinity enabling them to live in temporary water bodies formed after rainfall while the increase in the salinity of this water bodies is prospected due to evaporation during the period between two rainfalls. Diaw et al. (1989) reported that the variations in some abiotic factors like the temperature and the $\mathrm{pH}$ of water do not seem to have a strong influence on the ecology while rainfall has a great importance on the distribution and the density of molluscs. The variation in the salinity of water bodies has direct effects on the prevalence of parasites transmitted by snails living in such water bodies; Rogowski and Stockwell (2006) in their study about the relationship between salinity, snails, parasites and White Sands pupfish (Cyprinodon tularosa) in New Mexico State, reported that at the high salinity sites, springsnails were absent and pupfish trematode abundance was much lower, and fish condition was intermediate.

As a fact, the quantity of water and the drying out period of the ponds depend upon rain factors which rule the existence and the survival of the malacological fauna (Diaw et al., 1989). The present investigation declared that the ability of $B$. arabica snail to resist the complete dryness is limited, since $100 \%$ mortality was achieved 
after 36 hours in absence of lettuce leaves and after 48 hours in the presence of lettuce leaves (Table 3). The positive effects of the presence of lettuce leaves on the delaying the death of the snails may be due to the considerable humidity allowed by fresh lettuce leaves within the Petri dishes; since we observed that the snails were crawled and hidden below the lettuce leaves.

The snails in moist soil and supplied with fresh lettuce leaves, remain survive to 15 days without any death. In the case of snails in the moist soil and not supplied with fresh lettuce leaves, the survival was unaffected until $10^{\text {th }}$ day post-exposure, while further increases in exposure period resulted in reductions in survival up to $50 \%$ for snails exposed for 15 days (Table 4). Very interested observation was recorded -in the case of snails in moist soil- that is the snails were burrowed in the soil and buried themselves under moist soil grains. The resistance to drought has a great importance on the distribution and the density of molluscs. Diaw et al. (1989) studied the ecology and drought resistance of $B$. umbilicatus and B. senegalensis on 3 temporary ponds in the North-Sudan area (region of Tambacounda, Senegal) through two years. These ponds were dry during 6 to 8 months per year. However, the populations of molluscs regenerate regularly and reach their maximum number in the second part of the rainy season, a fact which presupposes a certain ability to resist drought.

Table (1): Percentage of mortality of Biomphalaria arabica exposed to various concentrations of $\mathrm{NaCl}$

\begin{tabular}{|c|c|c|c|c|c|c|c|c|c|c|}
\hline NaCl Conc. in \%o & 1 & 2 & 3 & 4 & 5 & 6 & 7 & 8 & 9 & 10 \\
\hline Mortality rate\% & 0 & $\mathbf{0}$ & $\mathbf{0}$ & $\mathbf{0}$ & $\mathbf{0}$ & $\mathbf{5 0}$ & $\mathbf{7 5}$ & $\mathbf{1 0 0}$ & $\mathbf{1 0 0}$ & $\mathbf{1 0 0}$ \\
\hline
\end{tabular}

Table (2): Percentage of mortality of Biomphalaria arabica exposed to concentrations of $\mathrm{NaCl}$ between 7.1 to $7.9 \%$

\begin{tabular}{|l|c|c|c|c|c|c|c|c|c|}
\hline NaCl Conc. in \%o & 7.1 & 7.2 & 7.3 & 7.4 & 7.5 & 7.6 & 7.7 & 7.8 & 7.9 \\
\hline Mortality rate\% & $\mathbf{8 5}$ & 100 & 100 & 100 & 100 & 100 & 100 & 100 & 100 \\
\hline
\end{tabular}

Table (3): Percentage of mortality of Biomphalaria arabica in completely dry soil

\begin{tabular}{|c|c|c|c|c|}
\hline Exposure time (in hours) & 12 & 24 & 36 & 48 \\
\hline In presence of lettuce leaves & 0 & 0 & 20 & 100 \\
\hline In absence of lettuce leaves & 0 & 20 & 100 & 100 \\
\hline
\end{tabular}

Table (4): Percentage of mortality of Biomphalaria arabica in moist soil

\begin{tabular}{|l|l|l|l|l|l|l|l|l|l|l|l|l|l|l|l|}
\hline Exposure time (in days) & 1 & 2 & 3 & 4 & 5 & 6 & 7 & 8 & 9 & 10 & 11 & 12 & 13 & 14 & 15 \\
\hline $\begin{array}{l}\text { In presence of lettuce } \\
\text { leaves }\end{array}$ & 0 & 0 & 0 & 0 & 0 & 0 & 0 & 0 & 0 & 0 & 0 & 0 & 0 & 0 & 0 \\
\hline $\begin{array}{l}\text { In absence of lettuce } \\
\text { leaves }\end{array}$ & 0 & 0 & 0 & 0 & 0 & 0 & 0 & 0 & 0 & 0 & 12 & 20 & 20 & 40 & 50 \\
\hline
\end{tabular}




\section{REFERENCES}

Arfaa, F. (1976). Studies on schistosomiasis in Saudi Arabia. Am. J. Trop. Med. Hyg., 25(2):295-298.

Badie A, Rondelaud D. (1982). Effect of parasitism on the resistance of Cionella lubrica Müller to temperature and desiccation. Ann. Rech. Vet., 13(1):61-7.

Brown, D. S. and Wright, C. A. (1980). Moulluscs of Saudi Arabia: Freshwater Moulluscs. Funa of Saudi Arabia,2: 341-358.

Chitsulo, L.; Engels D.; Montresor, A.; Savioli L. (2000). The global status of schistosomiasis and its control. Acta Trop. 77:41-51.

Diaw, O. T.; Seye, M.; Sarr Y. (1988). Resistance to drought of Bulinus mollucs, vectors of human and animal trematodosis in Senegal. I. Laboratory trials. Rev. Elev. Med. Vet. Pays. Trop., 41(3):289-91.

Diaw, O. T.; Seye, M.; Sarr Y. (1989). Resistance to drought of mollusks of the genus Bulinus, vectors of human and animal trematode infections in Senegal. II. Study under natural conditions in the North-Sudan area. Ecology and resistance to drought of Bulinus umbilicatus and B. senegalensis. Rev. Elev. Med. Vet. Pays. Trop.; 42(2):177-87.

Donnelly, F.A.; Appleton, C.C.; Schutte, C.H. (1983). The influence of salinity on certain aspects of the biology of Bulinus (Physopsis) africanus. Int. J. Parasitol., 13(6):539-45.

Donnelly, F.A.; Appleton, C.C. and Schutte, C.H. (1984). The influence of salinity on certain aspects of the biology of Bulinus (Physopsis) africanus. International Journal for Parasitology, 14(2): 113-120.

Gretillat, S.; Gaston, G. (1975). Remarks on the ecological adaptation of the snail aquatic fauna in saline medium of the Dallol ponds. (Republique du Niger). Ann Parasitol Hum Comp., 50(5):595-601.

Hart, B.T.; Bailey, P.; Edwards, R.; Hortle, K.; James, K.; McMahon, A.; Meredith, C.; Swadling, K.(1990). Effects of salinity on river, stream and wetland ecosystems in Victoria, Australia. Water Research, 24(9):1103-1117.

Hart, B.T.; Bailey, P.; Edwards, R.; Hortle, K.; James, K.; McMahon, A.; Meredith, C.; Swadling, K.(1991). A review of the salt sensitivity of the Australian freshwater biota. Hydrobiologia, 210:105-144.

Health Statistical Year Book of the Ministry of Health in KSA (2006).

Ibrahim, M.M. (2007). Prevalence and intensity of Angiostrongylus cantonensis in freshwater snails in relation to some ecological and biological factors. Parasite., 14(1):61- 70 .

Kefford, B.J.; Nugegoda, D.(2005). No evidence for a critical salinity threshold for growth and reproduction in the freshwater snail Physa acuta. Environ. Pollut., 134(3):377-383.

King, C. H.; Dickman K.; Tisch, D. J. (2005). Reassessment of the cost of chronic helmintic infection: a meta-analysis of disability-related outcomes in endemic schistosomiasis. Lancet 365:1561-1569.

Leveque, C; Pointier, JP; Toffart JL. (1978). Influence of some medium factors on the fecundity of Biomphalaria glabrata (Say, 1818) Mollusca, Pulmonata) in laboratory conditions. Ann Parasitol Hum Comp.,53 (4):393-402.

Lwambo, N. J.; Upatham, E.S.; Kruatrachue, M.; Viyanant, V. (1987). The hostparasite relationship between the Saudi Arabian Schistosoma mansoni and its intermediate and definitive hosts. 1. S. mansoni and its local snail host 
Biomphalaria arabica. Southeast Asian J. Trop. Med. Public. Health., 18(2):156-65.

Morley, N.J.; Lewis J.W. (2008). The influence of climatic conditions on long-term changes in the helminth fauna of terrestrial molluscs and the implications for parasite transmission in southern England. J Helminthol., 82(4):325-35.

Rogowski, D.L.; Stockwell, C.A. (2006). Parasites and salinity: costly tradeoffs in a threatened species. Oecologia,146(4):615-22.

Ross, A. G.; Bartley P. B.; Sleigh A. C.; Olds G. R.; Li Y.; Williams G. M.; McManus D. P.(2002). Schistosomiasis. N. Engl. J. Med. 346:1212-1220.

Williams, W. D. (1987). Salinization of rivers and streams: an important environmental hazard. Ambio, 16: 180-185.

Yasuraoka K. (1961).The effect of hydrogen ion concentration and salinity of water on extruding response and survival of Oncomelania nosophora, the vector snail of Schistosoma japonicum in Japan. Jpn. J. Med. Sci. Biol., 14:61-8.

\section{ARABIC SUMMARY}

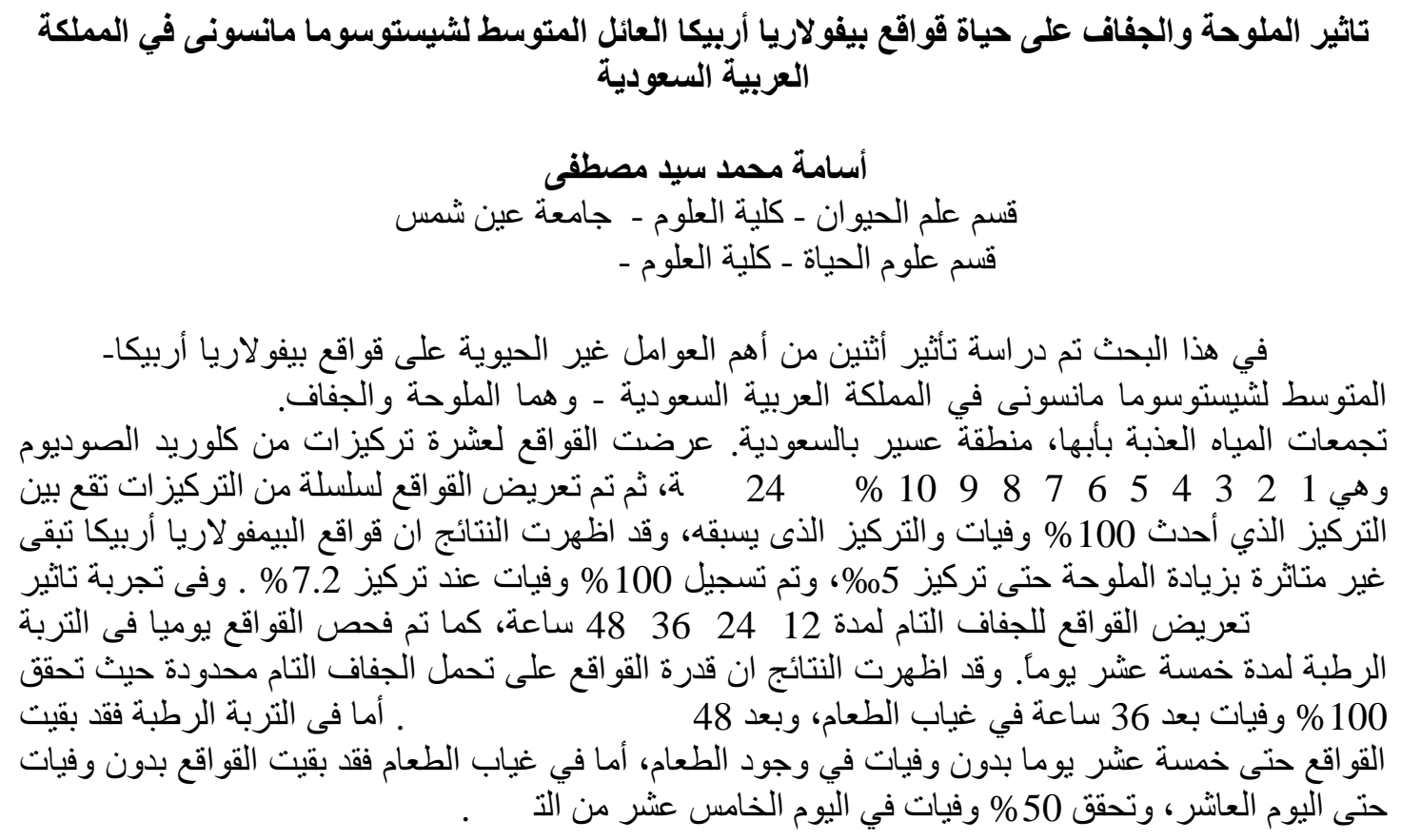

